\section{In-store interactive advertising screens: the effect of interactivity on impulse buying explained by self-agency}

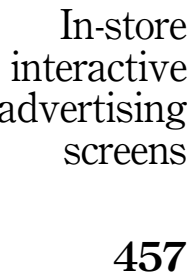

Anne Moes

FEB, University of Groningen, Groningen, The Netherlands and

DMCI, Amsterdam University of Applied Sciences, Amsterdam, The Netherlands

Marieke Fransen

Behavioral Science, Radboud Universiteit, Nijmegen, The Netherlands

Bob Fennis

FEB, University of Groningen, Groningen, The Netherlands

Tibert Verhagen

FBE, Amsterdam University of Applied Sciences, Amsterdam, The Netherlands, and Harry van Vliet

DMCI, Amsterdam University of Applied Sciences, Amsterdam, The Netherlands
Received 25 March 2021 Revised 4 June 2021 28 July 2021

Accepted 22 August 2021

\begin{abstract}
Purpose-Physical stores are increasingly dependent on impulse visits and the impulse purchases of passersby. Interactive advertising screens in store windows could help retailers increase impulse-visit urges and impulse-buying urges. However, the effects of interactive screens in physical surroundings have not been studied before. Therefore, this study aimed to examine the effect of interactive screens on impulse urges and gain insight into the underlying mechanism that explains the possible effect.

Design/methodology/approach - An interactive screen was placed in a store window. Using three field experiments, we studied the effect of interactivity-level (high vs low) on the impulse-visit and impulse-buying urges of passers-by, and the mediating role of self-agency in these effects.

Findings - Highly interactive (compared to less interactive) advertising screens in store windows positively affect impulse-visit and impulse-buying urges through self-agency. Retailers can therefore use interactive advertising screens to increase the number of impulse purchases if feelings of self-agency are activated.

Originality/value - This is the first study to examine the extent to which interactive screens in a store window enhance the impulse-visit and impulse-buying urges of passers-by and the mediating factor of these
\end{abstract}

\footnotetext{
(C) Anne Moes, Marieke Fransen, Bob Fennis, Tibert Verhagen and Harry van Vliet. Published by Emerald Publishing Limited. This article is published under the Creative Commons Attribution (CC BY 4.0) licence. Anyone may reproduce, distribute, translate and create derivative works of this article (for both commercial and non-commercial purposes), subject to full attribution to the original publication and authors. The full terms of this licence may be seen at http://creativecommons.org/ licences/by/4.0/legalcode.

We would like to thank Sewdath Ritoe for his help with data collection, DOBIT Solutions for providing and installing the interactive screens and Bij Mirjam for opening up her store to this experiment.

Funding: This work is supported by the Netherlands Organization for Scientific Research (NWO) [grant number: 023.011.008]; and by the Nationaal Regieorgaan Praktijkgericht Onderzoek SIA [RAAKmkbgrant]. The sponsors were not involved with any part of this paper and did not have any influence on the decision of whether to submit this paper.
} 
JRIM

16,3 effects. By conducting three field experiments, we achieved a high external validity and managed to share very reliable results owing to the replication of the findings.

Keywords Interactivity, Interactive screens, Store, Shop, Impulse buying, Impulse purchases, Impulse visits, Self-agency

Paper type Research paper

\section{Introduction}

The digital and physical worlds are increasingly merging in retail settings (Brynjolfsson et al., 2013). Typical online functionalities, such as interactive screens, have started entering physical store environments (e.g. Macy's, Adidas and Coca-Cola [1]; Pantano, 2016). The growing implementation of in-store interactive screens is, arguably, a logical result of (1) the habituation of consumers to shop and communicate through digital screens and other interactive in-store channels, (2) the increasingly active role that consumers play in the communication between brands and consumers and (3) the fact that interactivity has become a crucial element in marketing practice (Wang, 2021). Remarkably, the effects of such interactive screens in physical storefronts on persuasive outcomes, such as impulse buying, are unclear. Physical stores depend more than ever on impulse visits and impulse purchases of passers-by, owing to the increased competition with online shops (Mehra et al., 2017). Therefore, retailers should use new marketing stimuli, such as interactive innovations (e.g. Berry et al., 2010), to enhance impulse visits and impulse buying (Iyer et al., 2020). Based on a qualitative study, Pantano (2016) suggests that compared to online stores, offering interactive content in shopping windows may improve the competitive positions of physical stores. Although research on interactivity and impulsivity is highly valuable for both researchers and practitioners, the effects of interactive content in storefronts on such visits and purchases have not yet been examined. Therefore, this study aims to answer the following two questions: Can interactive screens in store-windows trigger impulse visits and impulse-buying urges? Moreover, what mechanism could explain this effect if so? By ascertaining the above, this study makes a unique contribution to the interactive-marketing literature and responds to the notion that more research on newly developed technologies in interactive marketing is necessary (Wang, 2021).

Based on previous research on interactivity in online contexts, interactive screens could arguably increase impulse-visit urges and impulse-buying urges (e.g. Kim and LaRose, 2004; Huang, 2016; Yim et al., 2017; Hu and Wise, 2021). However, these studies state either that interactivity and impulsivity are related to each other or that interactivity can positively affect persuasive outcomes in general. They do not provide any insights into the causal effect of interactivity on impulsivity. This study, however, conducts three field experiments and can therefore draw valid conclusions on the effect of interactivity on impulse-buying urges. Moreover, the abovementioned studies were conducted in an (experimental) online setting. Online shopping motivations and behavior do not necessarily correspond with offline shopping motivations and behavior (Haridasan and Fernando, 2018); therefore, it is still unclear whether the results of online studies hold in physical surroundings. Furthermore, instore shoppers (compared to online shoppers) are known to value interaction (Haridasan and Fernando, 2018). It is therefore remarkable that the effect of interactivity on impulse buying has not been studied in the context of physical shopping. Accordingly, the first aim of this study is to examine whether interactive screens in store windows positively affect impulsevisit urges and impulse-buying urges. This could provide relevant insights literature on interactive-marketing and for practice (Pantano, 2016).

This study's second aim is to gain insight into the underlying mechanisms that explain the possible effects of interactive screens on impulse-visit urges and impulse-buying urges. Although previous research on underlying mechanisms of impulse buying contributed 
significantly to the body of knowledge (e.g. Styvén et al., 2017), many studies assert that the antecedents, manifestations, underlying processes and consequences of impulse buying, particularly as they pertain to interactive choice contexts, are still poorly understood (Pham et al., 2017). This study aims to clarify which psychological state, triggered by interactivity, enhances impulse visits and impulse purchases. The agency model of customization (AMC; Sundar, 2008) suggests that interactive techniques could possibly enhance self-agency, which could increase positive attitudes toward displayed content. We will explore, with three field experiments in an Amsterdam-based clothing store, the extent to which self-agency contributes to the effects of interactivity on impulse-visit urges and impulse-buying urges. Herewith, we contribute to the interactive-marketing literature since self-agency is not studied before as a possible mediator that could explain the positive effects of interactivity.

\section{Theoretical background and hypotheses development}

\section{Impulse visits and impulse buying}

Impulse purchases can be defined as unplanned purchases accompanied by a sudden and strong urge to buy (Rook, 1987; Amos, 2014). Building on this definition, we define impulse visits as the unplanned entry into a physical store accompanied by a sudden strong urge to do so.

A meta-analysis on impulse buying (Amos, 2014) shows that antecedents of impulse buying can be categorized into dispositional factors (e.g. impulse-buying trait), sociodemographic factors (e.g. age) and situational factors (e.g. retail environment). Additionally, research shows that internal perceptions (e.g. time pressure), product characteristics (e.g. hedonic products) and product's promotion factors (e.g. discounts) affect impulse buying (see Khan et al., 2015). More specially, for the impulse buying of fashion items, Lee and Johnson (2010) stress the effect that store layout has on consumers' impulse buying. Compared to impulse buying, impulsive store visits are studied less often. However, it is known that store visits and impulse buying are often triggered by the same antecedents. For example, both store visits (Baek et al., 2020) and impulse buying (Sun and Yazdanifard, 2015) are stimulated by sensory experiences. It can be concluded that various antecedents affect both impulse buying and store visits. However, studies have not yet identified the effect of in-store interactive advertising screens on impulse-visit urges and impulse-buying urges.

\section{Effect of interactivity on impulse urges}

Interactive advertising screens can be classified under user-machine or user-message interactions, depending on the screen's features. In user-machine interaction, the emphasis lies on human interaction with computers. User-message interaction entails the possibility of users modifying a message (Liu and Shrum, 2002). Based on different interactivity types, Liu and Shrum (2002, p. 54) propose the following definition of interactivity: "The degree to which two or more communication parties can act on each other, on the communication medium, and on the messages and the degree to which such influences are synchronized." They also suggest that interactivity encompasses three dimensions: active control, two-way communication and synchronicity (also see Liu, 2003).

Even though mixed results on the effect of interactivity have been found (Wu, 2005), the notion that interactivity can affect persuasive outcomes for the better seems widely accepted (e.g. Chattaraman et al., 2014). For instance, studies demonstrate that interactivity positively affects constructs such as consumers' perceptions of usefulness and enjoyment (Yim et al., 2017), attitudes (Hu and Wise, 2021) and online buying activity (Kim and LaRose, 2004). A meta-analysis of 63 studies on web interactivity underlines this notion and shows that it is positively correlated with attitudes and desirable behavioral intentions of consumers (Yang

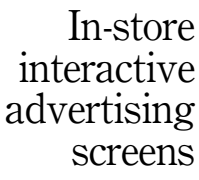


JRIM

16,3

and Shen, 2018). Additionally, Kakalejčík et al. (2020) show that positive experiences between companies and consumers with respect to online interactions can enhance consumers' (re) visit behavior and purchase behavior. Correspondingly, Bressolles et al. (2007) argue that website interactivity benefits feelings of gratification and could therefore induce buying impulses. They found that interactivity and impulse-buying buying urges are positively related. Additionally, through a survey, Huang (2016) showed that online interactive activity (browsing) and impulse buying are related.

It is interesting to study the extent to which the positive effects of interactivity in online settings will hold in offline settings, as online consumers differ from offline consumers. The former seek variety (e.g. Donthu and Garcia, 1999) and convenience (Monsuwé et al., 2004) more often than the latter. Additionally, some consumers prefer to interact in an online retail setting over interacting in an offline retail setting (Becker and Pizzutti, 2017). Moreover, some consumers can experience more risk when shopping online than when shopping offline (see Kim et al., 2020). These differences could imply that the positive effects of online interactivity do not necessarily apply to in-store interactivity. However, this study examines the effect of in-store interactive digital screens, which are in functionality and use comparable with interactive digital screens that are used for online shopping, such as laptop-screens. Therefore, we also expect a positive effect of interactivity as a functionality of digital screens in physical shop windows on impulsive consumer behavior.

Impulsive consumer behavior may manifest itself in various ways. In general, one may argue that such behavior manifests itself in terms of experiential shopping motives and behavior (where the experience itself is the goal of the behavior), as well as materialistic motives and behavior (where the acquired product is the goal of the behavior, see e.g. Carter and Gilovish, 2012). In the current context such experiential behavior translates into impulse store visits while materialistic behavior translates into impulse buying. There is no a priori reason to suspect that interactivity affects both types of impulsive consumer behavior differently (see Prediger et al., 2019). However, considering marketing implications, a separate examination of the effect of interactivity on both types is interesting. A visit does not necessarily result in a purchase (Vukadin et al., 2016). Likewise, with the possibility of online purchases store visits are no longer essential to impulse buying. We, therefore, explicitly distinguish impulse visits from impulse purchases and propose the following two hypotheses:

H1a. High interactivity leads to stronger impulse-visit urges than low interactivity.

H1b. High interactivity leads to stronger impulse-buying urges than low interactivity.

\section{Self-agency as a mediator in the effect of interactivity on impulse urges}

We further study the extent to which the positive effects of interactivity can be explained by self-agency. Self-agency refers to the feeling that one shapes her/his own actions and, therefore, is frequently intertwined with freedom of choice (Barlas and Obhi, 2013). According to Reactance Theory (Brehm, 1966), people are easier to persuade when they feel free to make their own choices (e.g. through interactive content, see Hu and Wise, 2021) than when they feel threatened in this freedom (e.g. by non-interactive ads; see Edwards et al., 2002). Correspondingly, Hu and Wise (2021) showed that the interactive elements of playable ads (indirectly) reduced perceived freedom threat, and therefore decreased consumers' resistance to the ads. Self-agency has been found to (unconsciously) strengthen a sense of authorship (e.g. Aarts et al., 2009), empowerment and mastery (e.g. Chiu et al., 2013) and may therefore be expected to represent the opposite of freedom threat. In line with $\mathrm{Hu}$ and Wise, we will examine to what extent interactivity enhances feelings of self-agency and, subsequently, if self-agency affects impulse buying. 
Customization is known to evoke feelings of self-agency (Sundar, 2008). The possibility of customization allows consumers to actively to adjust the content on, for example, an interface. Therefore, this option makes users part of the communication process rather than just the receivers, which, in turn, enhances feelings of self-agency (Sundar, 2008). Without implying that customization and interaction are the same, it could be argued that the option to change the communication process actively (e.g. changing the interface) plays an important role in both constructs. Furthermore, although it has not provided proof, the AMC (Sundar, 2008) proposes that interactivity techniques may enhance agency (also see Sundar and Marathe, 2010, p. 304).

This agency model also posits that self-agency results in positive attitudes toward the displayed content (Sundar, 2008). Attitudes toward products are known to correlate with impulse-buying behavior (Chen, 2008), indicating that self-agency may lead to higher impulse-visit urges and impulse-buying urges. Moreover, the literature reveals that people who experience a high sense of self-agency perceive messages as more important and are easier to persuade, to visit and buy impulsively for example, than people who experience a low sense of self-agency (Kang and Sundar, 2016), corresponding with Reactance Theory.

Similar as the reasoning for hypothesis $1 \mathrm{a}$ and $1 \mathrm{~b}$, there are no a priori reasons to suspect that interactivity affects both types of impulsive consumer behaviors through different processes (see e.g. Prediger et al., 2019). Based on the preceding, the following hypotheses are formulated (see Appendix 1 for conceptual model):

H2a. Self-agency mediates the effect of interactivity (high vs low) on impulse-visit urges.

$H 2 b$. Self-agency mediates the effect of interactivity (high vs low) on impulsebuying urges.

\section{Overview of studies}

We conducted a series of three field experiments (Experiments 1, 2a and $2 \mathrm{~b}$ ) to test the hypotheses. All experiments have a one-factor between-subject design with "level of interactivity" (low vs high) as the independent variable and "impulse-visit urge" and "impulse-buying urge" as dependent variables. We tested the hypotheses at a significance level of 0.05 . The experiments have a total sample size of 436 consumers. The required sample size was calculated a prior $i$ with G*Power in the $F$ tests family. The expected effect size $\left(f^{2}\right)$ we used to calculate the sample size was 0.15 since previous research found an average effect size of 0.17 when measuring the effect of marketing stimuli on impulse-buying behavior (Iyer et al., 2020). As there is just one predictor in our studies (interactivity), a total sample size of at least 89 participants per study was needed according to $\mathrm{G}^{*}$ Power tool, a requirement that we have met in all experiments.

The first experiment is both confirmative and explorative in nature since some additional exploratory variables were examined next to the hypotheses testing (see Experiment 1, "Measurements"). Both the second experiment and third experiment are solely confirmative in nature and were performed to check whether the results of Experiment 1 could be replicated. Replication is often undervalued, although of great importance for gaining confidence in the found results (McEwan et al., 2018). The data for Experiment 1 were collected in one week, the data for Experiments $2 \mathrm{a}$ and $2 \mathrm{~b}$ were collected in two weeks each. All three experiments had an approximately equal number of participants per day, except Sundays, when the shop was closed. All experiments included a manipulation check. Below we describe the method, results, and discussion for each experiment.

\section{Experiment 1}

Method. Stimulus material. An interactive screen (42 inches) was placed in the window of a women's clothing store located in a well-visited, high-end shopping street in Amsterdam, 
JRIM

16,3

Netherlands. The content and functionalities of the screen were specifically designed for the three experiments. In line with Liu and Shrum's (2002) conceptualization, screen interactivity was manipulated through active control, two-way communication and synchronicity. In both conditions, participants had to press play to start interacting with the screen. In the high-interactivity condition, participants could interact with the screen by swiping through the store's collection and zooming in on the displayed items (active control). Users could also like products by pressing on a "thumbs up" and interact with the screen by leaving a comment. Both were followed by a short reaction displayed on the screen (two-way communication). Additionally, in the high-interactivity condition, the screen responded immediately to the user's actions (synchronicity). In the low-interactivity condition, participants had fewer interaction options. After pressing play, they could only reverse the order in which items were shown instead of swiping through them. They could not zoom-in, like, or rate any products or the screen itself, and the response time of the screen on the user's action was delayed by a full second. The two conditions differed in the interactive features only. All other elements, such as content and size, were identical (see Appendix 2).

Participants. All participants $(N=102)$ were adults $\left(M_{\text {age }}=48.42, S D=19.96\right)$ and passers-by of the store where the interactive screen was located. Only women were approached to participate since the store in question only sells women's clothing. The participants fitted the natural group that could possibly be induced to buy impulsively at the store.

Procedure. The condition the participants were exposed to depended on the day they were asked to participate. The conditions were altered every day and week (also between the three experiments) to counterbalance the possible effect that "day of the week" could have on the dependent variables.

We hired student assistants to collect the data in the shopping street where the store was located. They attended a short training in advance, where they were trained on how to approach passers-by and what procedure to follow during data collection. After reading and signing an informed consent that, among other things, stated that participation was voluntary, participants were asked to use the screen in the store window. Since Experiment 1 was a partially explorative study, the participants were either asked to interact with the screen for one minute or for as long as they pleased, so it could be determined if a set interaction time would lead to different results than with no set time. Next, the participants filled in the questionnaire to measure the dependent and mediating variables. Afterward, they could voluntarily leave their email addresses to participate in a raffle to win a voucher worth 50 euros for the store in question. Last, all participants were debriefed and thanked for their participation.

Measurements. All constructs were measured using established measurement instruments from previous literature, on seven-point Likert scales $(1=$ totally disagree and $7=$ totally agree).

Manipulation check. More interactive options do not necessarily mean higher perceptions of interactivity (Voorveld et al., 2011). We further measured active control, two-way communication and synchronicity (Liu and Shrum, 2002), and overall perceived interactivity to ascertain whether the high-interactivity condition resulted in more feelings of interactivity than the low-interactivity condition [2]. See Table A1 in Appendix 3 for the manipulation-check measurements for each experiment.

Dependent variables. Impulse-buying urge was measured using a three-item scale (explained variance $=76.26 \%$, Cronbach's alpha $=0.84$ ). Two of the items were based on a scale used by Sultan et al. (2012), namely, "I feel a strong urge to buy (one of) the products that the screen displayed" and "I want (one of the) products that the screen displayed." The third item was added validate the definition of impulse buying, where unplanned needs play an important 
role: "I did not intend to buy (one of) the displayed products, but I now have the desire to do so."

We could not find an existing scale that measures impulse-visit urges. Therefore, we adjusted the scale we used to measure impulse-buying urges as follows: "I feel a strong urge to enter this store," "I want to visit this store," "I did not intend to visit this store, but now I do feel the desire to do so" (explained variance $=80.24 \%$, Cronbach's alpha $=0.88$ ).

Mediator. Self-agency was measured using the items "It felt like I was responsible for what happened on the screen" and "It felt like I was the one influencing what happened on the screen," based on a scale by Ruth et al. (2002) (explained variance $=90.01 \%$, Cronbach's alpha $=0.96$ ). See Table A2 in Appendix 3 for an overview of all key measurements that were used per experiment.

In addition to the constructs displayed in Table A2, we measured several other variables in Experiment 1 for exploratory reasons, such as feelings of product ownership and numerous emotions [3].

Results

The manipulation check showed that participants significantly scored higher $(t=-4.90$, $p<0.001)$ on active control in the high-interactivity condition $(M=4.34)$ than in the low-interactivity condition $(M=2.73)$. This was also the case for overall perceived interactivity $(M=3.67$ vs $M=2.42, t=-4.14, p<0.001)$. The manipulation succeeded.

To test H1a and H1b (high interactivity leads to stronger impulse-visit urges and impulse-buying urges than low interactivity), we performed a one-way ANOVA. Results show that both direct effects are not significant (impulse-visit urges: $F(1,96)=0.10$, $p=0.754$; impulse-buying urges: $F(1,96)=2.51, p=0.259)$. We also tested the proposed mediation hypotheses, such that self-agency mediates the effect of interactivity (high vs low) on impulse-visit urges and impulse-buying urges, using PROCESS's model number 4 (Hayes, 2017). These analyses show that interactivity does not affect impulse-visit urges through self-agency (H2a, 95\% CI: [-0.01 to 0.76]). Therefore, hypotheses $1 \mathrm{a}, 1 \mathrm{~b}$ and $2 \mathrm{a}$ are rejected.

We did find a positive effect of interactivity on self-agency $(b=1.22, S E=0.28,95 \% \mathrm{CI}$ : [0.66 to 1.78]) and of self-agency on impulse-buying urges $(b=0.31, S E=0.10, \mathrm{CI}$ : [0.11 to $0.51]$ ). Subsequently, we find a positive mediation effect of interactivity through self-agency on impulse-buying urges ( $b=0.38, S E=0.18,95 \%$ CI: [0.10 to 0.81$])$. Hypothesis $2 \mathrm{~b}$, selfagency mediates the effect of interactivity (high vs low) on impulse-buying urges, is therefore accepted. See Table A3 in Appendix 3 for the means of the outcome variables of each experiment.

\section{Discussion}

We did not find a direct effect of interactivity on impulse urges in Experiment 1. Nevertheless, we performed mediation analysis as a direct effect of $\mathrm{X}$ on $\mathrm{Y}$ is not required in modern mediation analysis: "Statistical mediation analysis has changed since the publication of Baron and Kenny (1986). The heyday of the causal steps 'criteria to establish mediation' approach is over. ... Modern mediation analysis emphasizes an explicit estimation of the indirect effect, ... . and an acknowledgment that evidence of a statistically significant association between $X$ and $Y$ is not necessary to talk about and model intervening variable processes ..." (Hayes, 2017, p. 146). The mediation analysis shows an indirect effect of interactivity on impulse-buying urges through self-agency. There are no effects found on impulse-visit urges. Since Experiment 1 was partially explorative in nature, we replicate the study in Experiment $2 \mathrm{a}$ and Experiment $2 \mathrm{~b}$ to confirm the results. 
JRIM

16,3
Experiment $2 a$ and experiment $2 b$

Method. Stimulus material and procedure. For Experiment $2 \mathrm{a}$ and Experiment 2b, the same stimulus material was used, and largely the same procedure was followed as in Experiment 1. Experiment 1 participants were asked to interact with the screen either for one minute or for as long as they pleased. Since interaction time did not influence the results, we decided to ask all participants in Experiments $2 \mathrm{a}$ and $2 \mathrm{~b}$ to interact with the screen for as long as they pleased to create a more natural situation for all participants. However, we set a minimal interaction time of 40 seconds, to provide the user with enough time to explore the condition.

Participants. The samples of Experiments $2 \mathrm{a}(N=153)$ and $2 \mathrm{~b}(N=190)$ were similar to those of Experiment 1. The mean ages in Experiment $2 \mathrm{a}$ and $2 \mathrm{~b}$ were $47.69(S D=17.79)$ and $49.37(S D=19.12)$, respectively. All participants were again adult passers-by and female. Seven of the participants in Experiment $2 \mathrm{~b}$ had already participated in Experiments 1 or $2 \mathrm{a}$ and were therefore excluded from further analyses $(N=183)$.

Measurements. Manipulation check. We used the same manipulation check as in Experiment 1 (see Table A1 in Appendix 3). In Experiment 2a active control had a Cronbach's alpha of 0.75 , two-way communication of 0.81 and synchronicity of 0.75 . In Experiment $2 \mathrm{~b}$ active control had a Cronbach's alpha of 0.82, two-way communication of 0.70 and synchronicity of 0.83 .

Dependent variables and mediators. As in Experiment 1, we measured impulse-buying urges (Experiment 2a: explained variance $=70.23 \%$, Cronbach's alpha $=0.79$; Experiment 2b: explained variance $=74.01 \%$, Cronbach's alpha $=0.82$ ), impulse-visit urges (Experiment 2a: explained variance $=73.40 \%$, Cronbach's alpha $=0.82$; Experiment $2 \mathrm{~b}$ : explained variance $=73.62 \%$, Cronbach's alpha $=0.82$ ), and self-agency (Experiment 2a: explained variance $=95.32 \%$, Cronbach's alpha $=0.91$; Experiment 2b: explained variance $=87.79 \%$, Cronbach's alpha $=0.86$; see Table A2 in Appendix 3). In Experiment 1, we also asked about some additional variables for exploratory reasons. Since these variables were not affected by interactivity, we did not measure them again in Experiment 2a and Experiment 2b. Therefore, these experiments can be considered as more confirmative in nature than Experiment 1 [4].

\section{Results}

Participants in Experiment 2a scored significantly higher on active control in the highinteractivity condition $(M=3.56)$ than in the low-interactivity condition $(M=2.92 ; t=-3.63$, $p<0.001)$. They also scored significantly higher on two-way communication $(M=3.64)$ in the high-interactivity condition than in the low interactivity condition $(M=2.33 ; t=-4.84$, $p<0.001)$, on synchronicity $(M=3.68$ vs $M=2.63, t=-4.05, p<0.001)$, and on overall perceived interactivity $(M=4.31$ vs $M=2.79, t=-5.22, p<0.001)$. Also in Experiment 2b participants scored significantly higher on all manipulation-check variables in the highinteractivity condition than in the low-interactivity condition (active control: $M=4.45$ vs $M=2.69, t=-6.35, p<0.001$; two-way communication: $M=3.58$ vs $M=2.59, t=-3.81$, $p<0.001$; synchronicity: $M=3.98$ vs $M=2.98, t=-3.47, p=0.001$; overall perceived interactivity: $M=4.31$ vs $M=2.84, t=-5.76, p<0.001$ ). The manipulation in Experiments $2 \mathrm{a}$ and $2 \mathrm{~b}$ therefore succeeded.

In line with the results of Experiment 1, a one-way ANOVA showed that there is no direct effect of interactivity on impulse-visit urges $(F(1,151)=0.92, p=0.338)$ and impulse-buying urges $(\mathrm{H} 1 \mathrm{~b}, F(1,151)=0.69, p=0.406)$ in Experiment 2a. Similarly, also in Experiment $2 \mathrm{~b}$ no direct effects of interactivity on impulse-visit urges $(F(1,188)=1.12, p=0.292)$ and impulse-buying urges $(F(1,188)=3.18, p=0.076)$ were found. Therefore, hypotheses $1 \mathrm{a}$ and $1 \mathrm{~b}$ are rejected.

The mediation hypotheses were again tested in PROCESS. Experiment $2 \mathrm{a}$ shows a positive significant effect of interactivity on self-agency $(b=1.79, S E=0.26,95 \% \mathrm{CI}$ : $[1.28$ to 2.30]) and of self-agency on impulse-visit urges ( $b=0.17, \mathrm{SE}=0.07,95 \% \mathrm{CI}$ : [0.03 to 0.32]). Subsequent to these results, but opposite to the results of Experiment 1, we found a 
significant positive indirect effect of interactivity on impulse-visit urges through self-agency in Experiment 2a ( $b=0.31, S E=0.15,95 \%$ CI: [0.03 to 0.62]). Experiment $2 \mathrm{~b}$ shows similar results. There is a positive effect of interactivity on self-agency $(b=1.38, S E=0.24,95 \% \mathrm{CI}$ : [0.92 to 1.85]) and a positive effect of self-agency on impulse-visit urges $(b=0.37, S E=0.07$, $95 \%$ CI: [0.24 to 0.51]). Subsequently, we also find in Experiment $2 \mathrm{~b}$ a significant positive indirect effect of interactivity on impulse visit urges through self-agency $(b=0.52, S E=0.14$, $95 \%$ CI: [0.28 to 0.82]). Based on Experiment 2a and 2b, hypothesis 2a, self-agency mediates the effect of interactivity (high vs low) on impulse-visit urges, is therefore accepted.

Hypothesis $2 \mathrm{~b}$, self-agency mediates the effect of interactivity (high vs low) on impulsebuying urges, is - in line with the outcomes of Experiment 1 - also accepted based on the results from Experiments $2 \mathrm{a}$ and $2 \mathrm{~b}$. Experiment $2 \mathrm{a}$ shows that interactivity has a positive effect on self-agency ( $b=1.79, S E=0.26,95 \% \mathrm{CI}$ : [1.28 to 2.30$])$, and self-agency has a positive effect on impulse-buying urges ( $b=0.25, S E=0.06,95 \%$ CI: [0.12 to 0.37]). Subsequently, there is an indirect effect of interactivity through self-agency on impulsebuying urges $(b=0.44, S E=0.12,95 \% \mathrm{CI}$ : [0.21 to 0.69]). Experiment $2 \mathrm{~b}$ also shows an effect of interactivity on self-agency $(b=1.38, S E=0.24,95 \% \mathrm{CI}$ : [0.92 to 1.85$])$ and of self-agency on impulse-buying urges ( $b=0.31, S E=0.06,95 \% \mathrm{CI}$ : [0.19 to 0.43$]$ ). Again, an indirect effect of interactivity on impulse-buying urges through self-agency was found $(b=0.43, S E=0.13$, 95\% CI: [0.21 to 0.70]). See Table A3 in Appendix 3 for the means.

\section{Discussion}

Experiments 2a and 2b, similar to Experiment 1, show no direct effect of interactivity but do show an indirect effect of interactivity on impulse-buying urges through self-agency. Experiments $2 \mathrm{a}$ and $2 \mathrm{~b}$ find the same pattern for impulse-visit urges in PROCESS, namely, a positive indirect effect of interactivity through self-agency on impulse-visit urges. This result was not observed in Experiment 1, which may be attributed to its slightly smaller sample size compared to the sample sizes of the other two experiments. This reasoning seems plausible as the mediation effect of interactivity on impulse-visit urges through self-agency in Experiment 1 was close to significant (95\% CI: [-0.01 to 0.76]).

\section{General discussion \\ Conclusion}

Interactive screens in stores are on the rise and could help retailers strengthen their competitive positions (Pantano, 2016). This study examines the extent to which interactive screens in a clothing store's window enhance impulse-visit urges and impulse-buying urges of passers-by, and what mediates this effect. We performed three field experiments: Experiment 1 was partially explorative, Experiment 2a was confirmative and in Experiment $2 \mathrm{~b}$ replicated the second experiment, to ensure the reliability of the results (McEwan et al., 2018). We showed, for the first time, that self-agency functions as an underlying mechanism that explains the positive effect of interactivity on impulse-visit and impulse-buying urges.

\section{Theoretical implications}

This study examined the effects of interacting with a digital screen in a real-life shopping environment, a physical store. Previous studies on interactivity mostly focused on (experimental) online settings (e.g. Kim and LaRose, 2004; Lee, 2005; Macias, 2003). Surprisingly, previous studies on interactivity scarcely investigated the effects on impulsevisit urges and impulse-buying urges. Furthermore, self-agency has not been studied before as a possible mediator in the effect of interactivity on impulse buying. Therefore, this paper also contributes to the literature by providing insights into the underlying impulse-buying

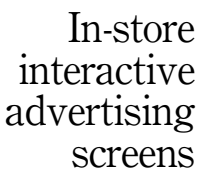

465 
JRIM

16,3 mechanisms. Following this, we responded to the notion that the inner psychological states impulse buying derives from are complex and not yet totally clear (Pham et al., 2017).

In two out of three experiments we found an indirect effect of interactivity on impulse-visit urges through self-agency. In Experiment 1, we only found an indirect effect of interactivity through self-agency on impulse-buying urges, and not on impulse-visit urges. As discussed previously, the lack of this effect could be attributed to the smaller sample size of Experiment 1 (compared to Experiments 2a and 2b). An alternative explanation could be that the explaining mechanism in the effect of interactivity on impulse visit urges partially differs from the explaining mechanism in the effect of interactivity on impulse buying urges. So far, the literature did not give reasons to suspect that the effect of interactivity on both dependent variables would be explained by different mediators (see e.g. Prediger et al., 2019). However, the results of Experiment 1 indicate that it would be interesting to explore the existence of different mediators in the effect of interactivity on impulse visits and impulse purchases.

In line with our expectations, all three field experiments showed that self-agency functions as a mediator in interactivity's effect on impulse-buying urges. This corresponds with the AMC, which suggests that interactivity techniques could enhance agency and that self-agency could affect attitudes toward displayed items (Sundar, 2008). By proving that self-agency can enhance impulse urges, we introduce the term "the self-agency paradox," which means that when people think they are in charge of what happens and feel as though they cause certain events (self-agency), they are actually less in charge than they assume (Kang and Sundar, 2016) and are more likely to yield to their impulses. A possible explanation for this paradox can be found in Reactance Theory, which states that people who feel free to make their own choices (which is often intertwined with feelings of self-agency (Barlas and Obhi, 2013)) are easier to persuade. However, additional research must be conducted to substantiate the existence of the self-agency paradox.

We did not find the proposed direct effect of interactivity on impulse-visit urge and impulsebuying urge. A possible explanation for this is that interactivity could both and simultaneously have a negative and positive effect on impulse urges. It appears that the residual direct effect of interactivity on impulse visit urges and impulse buying urges, when taking self-agency into account, turns out to be negative in two out of three of our experiments (Experiment $1^{\text {buying. }}$ $B=-0.69, S E=0.30,95 \%$ CI: $[-1.29$ to -0.09$], p=0.025$; Experiment $2 \mathrm{a}^{\text {visit. }}: B=-0.54$, $S E=0.27, \mathrm{CI}:[-1.07$ to -0.01$], p=0.046$; Experiment $2 \mathrm{a}^{\text {buying: }} B=-0.62, S E=0.23,95 \% \mathrm{CI}$ : $[-1.06$ to -0.17$], p=0.007)$. This means that two processes could be triggered by interactivity that cancel each other out, whereof self-agency is the process that explains the positive effect of interactivity. Future studies should examine the possible mediators that could explain the negative effect of interactivity, such as involvement (see Liu and Shrum, 2013).

\section{Implications for practice}

This study provides practical contributions to professionals working in the retail, marketing and advertising fields. We gained more relevant and externally valid information for retailers that run a physical store by conducting field experiments. Hereby, this study explicitly distinguished impulse-visit urges from impulse-buying urges. We proposed that impulse visits are a manifestation of experiential shopping motives and behavior while impulse purchases would pertain to more materialistic motives and behavior. Since (impulsive) store visits do not necessarily lead to (impulsive) purchases and vice versa, it is interesting for interactive marketing practitioners to explicitly make this distinction.

It is relevant to know that interactive screens in store-windows could increase the number of people who visit their store spontaneously and buy something there impulsively, depending on whether feelings of self-agency are nourished. This insight is important as physical stores are increasingly dependent on impulse visits and impulse purchases (Mehra et al., 2017). Interactive screens are already used in physical stores (Pantano, 2016). However, 
except for one qualitative study that suggests that interactive screens could strengthen physical stores' competitive position (Pantano, 2016), no research was conducted on the actual effects of these kinds of screens. The use of interactive screens in storefronts of high-end clothing stores could be beneficial for retailers if the screens stimulate a sense of self-agency with the user, resulting in impulse visits and impulse purchases.

\section{Limitations and future research directions}

Although this study contributed to the literature and practice in multiple ways, it entails some critical limitations. First, it evaluates urges rather than actual behaviors. Measuring impulse behavior is challenging as it is difficult to observe whether a behavior is impulsive. Studies on impulse-buying behavior (e.g. Mohan et al., 2013) often approach people who already bought something and then afterward ask if these purchases were planned (vs unplanned) and whether or not the purchase process was accompanied by a sudden strong urge or desire to buy the product. The disadvantage of this method is that it possibly leads to incorrect answers of the respondents since they are likely to justify their behavior (e.g. James and Rentsch, 2004) by, for example, falsely telling themselves and others they were already planning to buy the purchased item that was actually bought impulsively. Asking people about urges and desires can also be criticized when those urges have already been fulfilled with the product's purchase. We questioned participants just before a possible impulsive action was taken and asked about their current urges, making the results more valid. However, the consequences were that we could not observe their visiting and buying behavior afterward, as we had already made the participants aware of their urges, which arguably interferes with acting impulsively. Therefore, future research should focus on developing a new method to measure impulse-buying behavior. It would be also interesting to study the effect of online interactivity vs offline interactivity, to establish their relative effects on impulse urges and impulse behavior.

A second limitation of this study is the forced usage of the screens. In addition to the practical issue of needing enough passers-by to interact with the screen, we asked participants to use the screen to counter self-selection. External validity can be improved when passers-by are not explicitly asked to use the screen. Without forced usage, it is likely that more information-seeking passers-by would have used the screen (Qin, 2020), which may have affected the outcomes of the experiments. Future studies should consider only addressing passers-by who use interactive screens voluntarily, as this is a more natural shopping situation. Nevertheless, since this study only used field experiments, the external validity is relatively high (in comparison to lab experiments); the experiments were conducted in a real-life shopping street, the interactive screen was placed in an actual shop and all participants were real passers-by and were therefore not asked to visit but just to participate in the study. This makes this study highly valuable in both practice and science.

This study shows that interactivity (through interactive screens in store windows) can positively affect impulse visits and impulse purchases, if the underlying mechanism, "feelings of self-agency", is activated. This is an interesting and relevant insight that should be examined extensively. Therefore, we encourage other researchers to determine if they can replicate our findings in different settings, search for other mediators that may explain the positive (and possibly negative) effects and explore the role of possible moderators that could aggravate the effect of interactivity, such as consumer-brand identity (Graham and Wilder, 2020). This study can serve as a foundation for future research as it is the first to examine the effect of interactive screens in store windows on impulse urges. It is also the first to show that self-agency is an important explanation for the positive effects of interactivity.

\section{Notes}

1. https://www.ecommercenews.nl/winkels-proberen-interactieve-touchscreens/, retrieved 20 March 2019.

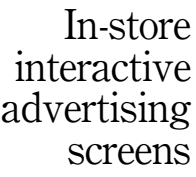

467 
JRIM

16,3

2. Since the Cronbach's alpha of the two-way communication scale and the synchronicity scale appeared to be insufficient in the first experiment, we proceeded the manipulation check analyses in Experiment 1 only with the active-control construct (Cronbach's alpha $=0.77$ ). The low Cronbach's alpha for "twoway communication" and "synchronicity" were likely caused by the fact that many participants overlooked some of the items that measured two-way communication and synchronicity. Therefore, we made it mandatory in Experiments 2 and 3 to answer all manipulation-check questions.

3. The first author can be contacted for a full list of these explorative variables. We did not find any significant results of these explorative variables and will not mention these further in this study.

4. For exploratory purposes, we also included state mindfulness and private self-awareness in Experiment $2 \mathrm{~b}$ to explore if these variables would explain a possible negative effect of interactivity on impulse-visit urges and on impulse-buying urges. Process' model $\mathrm{nr} 4$ shows that both mindfulness and self-awareness did not function as a mediator in these effects.

\section{References}

Aarts, H., Custers, R. and Marien, H. (2009), "Priming and authorship ascription: when nonconscious goals turn into conscious experiences of self-agency", Journal of Personality and Social Psychology, Vol. 96 No. 5, pp. 967-979.

Amos, C., Holmes, G.R. and Keneson, W.C. (2014), "A meta-analysis of consumer impulse buying", Journal of Retailing and Consumer Services, Vol. 21 No. 2, pp. 86-97, doi: 10.1016/j.jretconser. 2013.11.004.

Baek, E., Choo, H.J., Wei, X. and Yoon, S.Y. (2020), "Understanding the virtual tours of retail stores: how can store brand experience promote visit intentions?", International Journal of Retail and Distribution Management, Vol. 48 No. 7, doi: 10.1108/IJRDM-09-2019-0294.

Barlas, Z. and Obhi, S. (2013), "Freedom, choice, and the sense of agency", Frontiers in Human Neuroscience, Vol. 7, p. 514, doi: 10.3389/fnhum.2013.0051.

Baron, R.M. and Kenny, D.A. (1986), "The moderator-mediator variable distinction in social psychological research: conceptual, strategic, and statistical considerations", Journal of Personality and Social Psychology, Vol. 51 No. 6, p. 1173.

Becker, L.C. and Pizzutti, C. (2017), "C2C value creation: social anxiety and retail environment", Journal of Research in Interactive Marketing, Vol. 11 No. 4, p. 398 415, doi: 10.1108/JRIM-10-2016-0106.

Berry, L.L., Bolton, R.N., Bridges, C.H., MeyerParasuraman, J.A. and Seiders, K. (2010), "Opportunities for innovation in the delivery of interactive retail services", Journal of Interactive Marketing, Vol. 24 No. 2, pp. 155-167, doi: 10.1016/j.intmar.2010.02.001.

Brehm, J.W. (1966), A Theory of Psychological Reactance, Academix Press, New York, NY.

Bressolles, G., Durrieu, F. and Giraud, M. (2007), "The impact of electronic service quality's dimensions on customer satisfaction and buying impulse", Journal of Consumer Behavior, Vol. 6 No. 1, pp. 37-56, doi: 10.1362/147539207X198365.

Brynjolfsson, E., Hu, Y.J. and Rahman, M.S. (2013), Competing in the Age of Omnichannel Retailing, MIT, Cambridge.

Carter, T.J. and Gilovich, T. (2012), "I am what I do, not what I have: the differential centrality of experiential and material purchases to the self", Journal of Personality and Social Psychology, Vol. 102 No. 6, pp. 1304-1307.

Chattaraman, V., Kwon, W.S., Gilbert, J.E. and Li, Y. (2014), "Virtual shopping agents: persona effects for older users", Journal of Research in Interactive Marketing, Vol. 8 No. 2, pp. 144-162, doi: 10. 1108/JRIM-08-2013-0054.

Chen, T. (2008), "Impulse purchase varied by products and marketing channels", Journal of International Management Studies, Vol. 3 No. 1, pp. 154-161.

Chiu, M.Y.L., Davidson, L., Lo, W.T.L., Yiu, M.G.C. and Ho, W.W.N. (2013), "Modeling self- agency among people with schizophrenia: empirical evidence for consumer-based recovery", Psychopathology, Vol. 46 No. 6, pp. 413-420. 
Donthu, N. and Garcia, A. (1999), "The internet shopper", Journal of Advertising Research, Vol. 39 No. 3, pp. 53-62.

Edwards, S.M., Li, H. and Lee, J.H. (2002), "Forced exposure and psychological reactance: antecedents and consequences of the perceived intrusiveness of pop-up ads", Journal of Advertising, Vol. 31 No. 3, pp. 83-95.

Graham, K.W. and Wilder, K.M. (2020), "Consumer-brand identity and online advertising message elaboration: effect on attitudes, purchase intent and willingness to share", Journal of Research in Interactive Marketing, Vol. 14 No. 1, pp. 111-132.

Haridasan, A.C. and Fernando, A.G. (2018), "Online or in-store: unravelling consumer's channel choice motives”, Journal of Research in Interactive Marketing, Vol. 12 No. 2, pp. 215-230, doi: 10.1108/ JRIM-07-2017-0060.

Hayes, A.F. (2017), Introduction to Mediation, Moderation, and Conditional Process Analysis: A Regression-Based Approach, Guilford publications.

$\mathrm{Hu}, \mathrm{X}$. and Wise, K. (2021), "How playable ads influence consumer attitude: exploring the mediation effects of perceived control and freedom threat", Journal of Research in Interactive Marketing, Vol. 15 No. 2, available at: http://doi-org.rps.hva.nl:2443/10.1108/JRIM-12-2020-0269.

Huang, L.T. (2016), "Flow and social capital theory in online impulse buying", Journal of Business Research, Vol. 69 No. 6, pp. 2277-2283, doi: 10.1016/j.jbusres.2015.12.042.

Iyer, G.R., Blut, M., Xiao, S.H. and Grewal, D. (2020), "Impulse buying: a meta-analytic review", Journal of the Academy of Marketing Science, Vol. 48 No. 3, pp. 1-21, doi: 10.1007/s11747-019-00670-w.

James, L.R. and Rentsch, J.R. (2004), "Justify to explain the reasons why: a conditional reasoning approach to understanding motivated behavior", Personality and Organizations, pp. 223-250.

Kakalejčík, L., Bucko, J. and Danko, J. (2020), "Impact of direct traffic effect on online sales", Journal of Research in Interactive Marketing, Vol. 14 No. 1, pp. 17-32, doi: 10.1108/JRIM-01-2019-0012.

Kang, H. and Sundar, S.S. (2016), "When self is the source: effects of media customization on message processing”, Media Psychology, Vol. 19 No. 4, pp. 561-588, doi: 10.1080/15213269.2015.1121829.

Khan, M.T., Humayun, A.A. and Sajjad, M. (2015), "Factors affecting impulse buying and percentage of impulse buying in total purchasing", International Journal of Information, Business and Management, Vol. 7 No. 1, pp. 254-370.

Kim, J. and LaRose, R. (2004), "Interactive e-commerce: promoting consumer efficiency or impulsivity? ", Journal of Computer-Mediated Communication, Vol. 10 No. 1, doi: 10.1111/j.1083-6101.2004. tb00234.x.

Kim, J.M., Kim, M. and Key, S. (2020), "When profile photos matter: the roles of reviewer profile photos in the online review generation and consumption processes", Journal of Research in Interactive Marketing, Vol. 14 No. 4, pp. 391-412.

Lee, J. and Johnson, K.K. (2010), "Buying fashion impulsively: environmental and personal influences", Journal of Global Fashion Marketing, Vol. 1 No. 1, pp. 30-39.

Lee, T. (2005), "The impact of perceptions of interactivity on customer trust and transaction intentions in mobile commerce", Journal of Electronic Commerce Research, Vol. 6 No. 3, pp. 165-180.

Liu, Y. and Shrum, L.J. (2002), "What is interactivity and is it always such a good thing? Implications of definition, person, and situation for the influence of interactivity on advertising effectiveness", Journal of Advertising, Vol. 31 No. 4, pp. 53-64, doi: 10.1080/00913367.2002.10673685.

Liu, Y. and Shrum, L.J. (2013), “A dual-process model of interactivity effects”, Journal of Advertising, Vol. 38 No. 2, pp. 53-68.

Liu, Y. (2003), "Developing a scale to measure the interactivity of websites", Journal of Advertising Research, Vol. 43 No. 2, pp. 207-216.

Macias, W. (2003), "A beginning look at the effects of interactivity, product involvement and web experience on comprehension: brand web sites as interactive advertising", Journal of Current Issues and Research in Advertising, Vol. 25 No. 2, pp. 31-44, doi: 10.1080/10641734.2003.10505147. 
JRIM 16,3

McEwan, B., Carpenter, C.J. and Westerman, D. (2018), "On replication in communication science", Communication Studies, Vol. 69 No. 3, pp. 235-241.

Mehra, A., Kumar, S. and Raju, J.S. (2017), “Competitive strategies for brick-and-mortar stores to counter showrooming”, Management Science, Vol. 64 No. 7, pp. 3076-3090, doi: 10.1287/mnsc.2017.2764.

Mohan, G., Sivakumaran, B. and Sharma, P. (2013), "Impact of store environment on impulse buying behavior", European Journal of Marketing, Vol. 47 No. 10, pp. 1711-1732, doi: 10.1108/EJM-032011-0110.

Monsuwé, T.P.Y., Benedict, G.C. and Ko de Ruyter, D. (2004), "What drives consumers to shop internet? A literature review”, International Journal of Service Industry Management, Vol. 15 No. 1, pp. 102-121.

Pantano, E. (2016), "Engaging consumer through the storefront: evidences from integrating interactive technologies", Journal of Retailing and Consumer Services, Vol. 28, pp. 149-154, doi: 10.1016/j.jretconser.2015.09.007.

Pham, N., Minor, M., Li, Y., Pham, H., Hossain, T. and Wang, H. (2017), "The buying impulse and perceptions of the physical self", Theoretical Economics Letters, Vol. 7 No. 7, pp. 1899-1924.

Prediger, M., Huertas-Garcia, R. and Gázquez-Abad, J.C. (2019), "Store flyer design and the intentions to visit the store and buy: the moderating role of perceived variety and perceived store image", Journal of Retailing and Consumer Services, Vol. 51, pp. 202-211.

Qin, Y.S. (2020), "Fostering brand-consumer interactions in social media: the role of social media uses and gratifications", Journal of Research in Interactive Marketing, Vol. 14 No. 3, pp. 337-354, doi: 10.1108/JRIM-08-2019-0138.

Rook, D.W. (1987), “The buying impulse”, Journal of Consumer Research, Vol. 14 No. 2, pp. 189-199, doi: 10.1086/209105.

Ruth, J.A., Brunel, F.F. and Otnes, C.C. (2002), "Linking thoughts to feelings: investigating cognitive appraisals and consumption emotions in a mixed-emotions context", Journal of the Academy of Marketing Science, Vol. 30 No. 1, pp. 44-58.

Styvén, M.E., Foster, T. and Wallström, A. (2017), "Impulse buying tendencies among online shoppers in Sweden”, Journal of Research in Interactive Marketing, Vol. 11 No. 4, pp. 416-431, doi: 10.1108/ JRIM-05-2016-0054.

Sultan, A.J., Joireman, J. and Sprott, D.E. (2012), "Building consumer self-control: the effect of selfcontrol exercises on impulse buying urges”, Marketing Letters, Vol. 23 No. 1, pp. 61-72, doi: 10. 1007/s11002-011-9135-4.

Sun, T.R. and Yazdanifard, R. (2015), "The review of physical store factors that influence impulsive buying behavior", Economics, Vol. 2 No. 9, pp. 1048-1054.

Sundar, S.S. (2008), "Self as source: agency and customization in interactive media", in Mediated Interpersonal Communication, Routledge, pp. 72-88.

Sundar, S.S. and Marathe, S.S. (2010), "Personalization versus customization: the importance of agency, privacy, and power usage", Human Communication Research, Vol. 36 No. 3, pp. 298-322.

Voorveld, H.A.M., Neijens, P.C. and Smit, E.G. (2011), "The relation between actual and perceived interactivity”, Journal of Advertising, Vol. 40 No. 2, pp. 77-92, doi: 10.2753/JOA0091-3367400206.

Vukadin, A., Lemoine, J.F. and Badot, O. (2016), "Opportunities and risks of combining shopping experience and artistic elements in the same store: a contribution to the magical functions of the point of sale", Journal of Marketing Management, Vol. 32 Nos 9-10, pp. 944-964.

Wang, C.L. (2021), "New frontiers and future directions in interactive marketing: inaugural Editorial", Journal of Research in Interactive Marketing, Vol. 15 No. 1, pp. 1-9.

$\mathrm{Wu}, \mathrm{G}$. (2005), "The mediating role of perceived interactivity in the effect of actual interactivity on attitude toward the website", Journal of Interactive Advertising, Vol. 5 No. 2, pp. 29-39.

Yang, F. and Shen, F. (2018), "Effects of web interactivity: a meta- analysis", Communication Research, Vol. 45 No. 5, pp. 635-658, doi: 10.1177/0093650217700748. 
Yim, M.Y.C., Chu, S.C. and Sauer, P.L. (2017), "Is augmented reality technology an effective tool for e-commerce? An interactivity and vividness perspective", Journal of Interactive Marketing, Vol. 39, pp. 89-103, doi: 10.1016/j.intmar.2017.04.001.

\section{Appendix 1}

Conceptual model

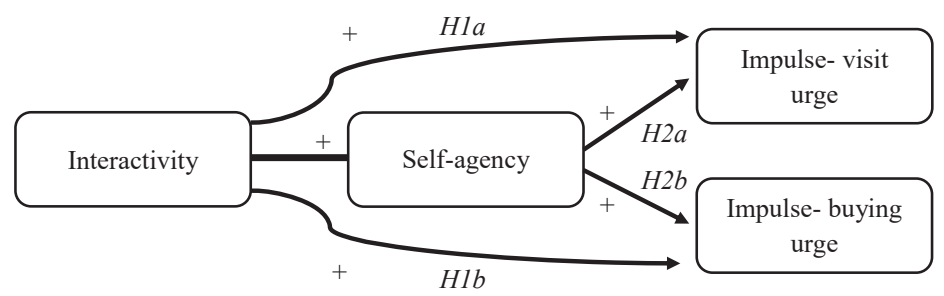

\section{Appendix 2}

Impression of the conditions

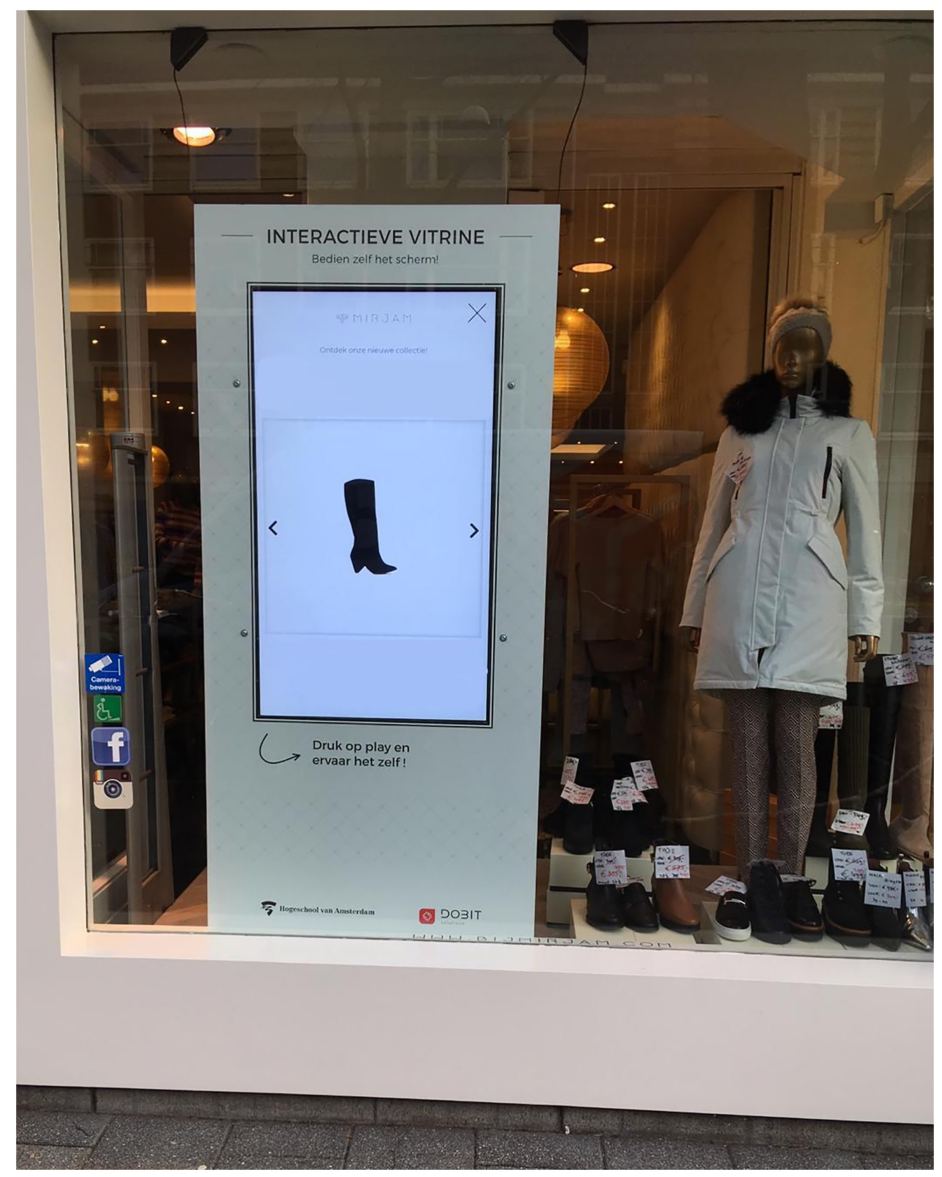

\section{In-store interactive advertising \\ screens}

Figure A1.

Conceptual model hypotheses
Plate A1.

Low-interactivity condition after the participant pressed play, where levels of

control, two-way communication and synchronicity were kept low 


\section{JRIM 16,3}

Plate A2.

High-interactivity condition after the participant pressed play, where levels of control, two-way

communication and synchronicity were higher

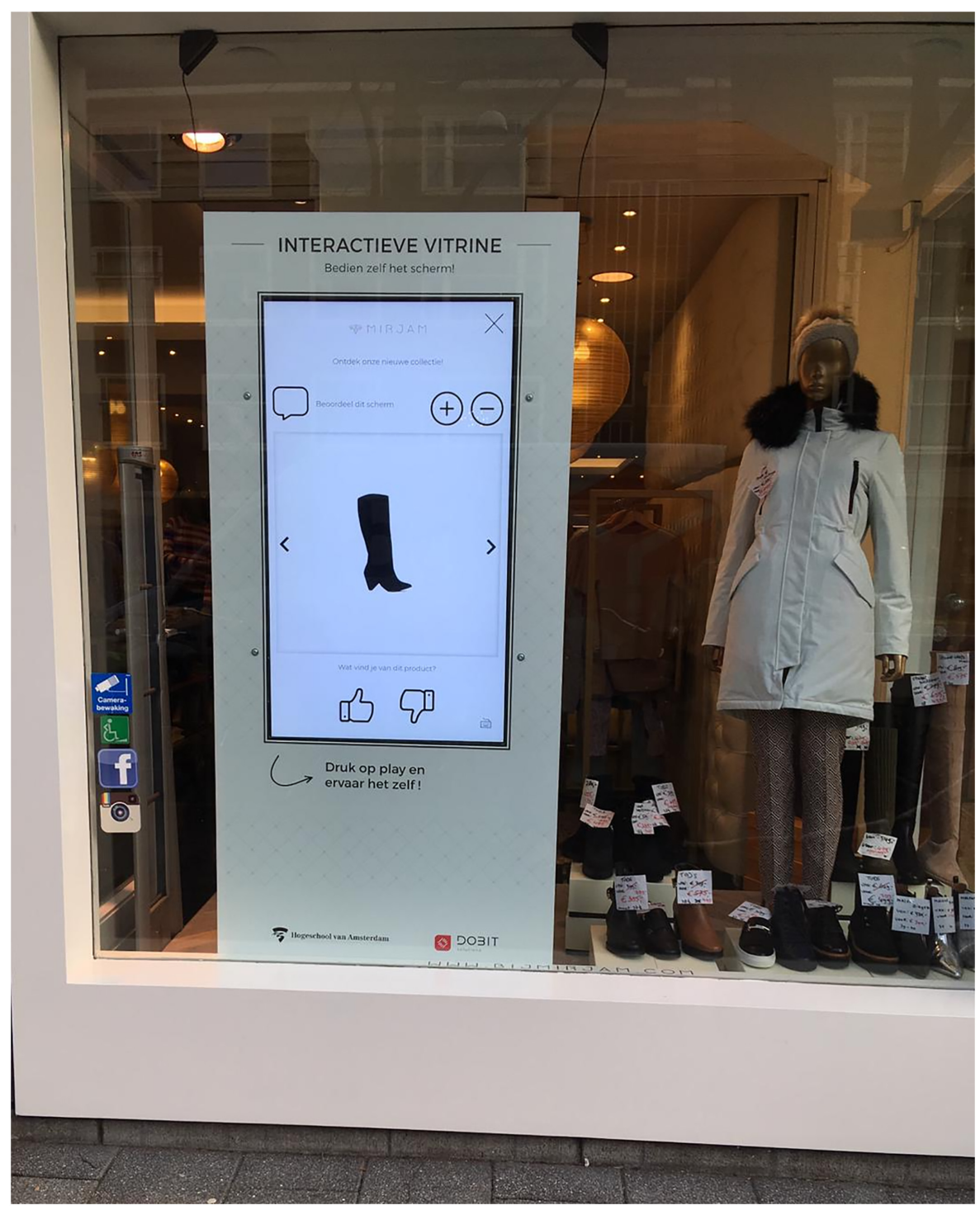


Appendix 3

Scale measurements and means

\section{In-store \\ interactive advertising \\ screens

\begin{tabular}{|c|c|c|c|}
\hline Construct & Items & $\begin{array}{l}\text { Cronbach's alpha } \\
1 / 2 \mathrm{a} / 2 \mathrm{~b}\end{array}$ & $\begin{array}{l}\text { Based on } \\
\text { scales used by }\end{array}$ \\
\hline Active control & $\begin{array}{l}\text { I felt that I had control over the screen; While interacting } \\
\text { with the screen, I could browse at my own pace; While } \\
\text { interacting with the screen, I had absolutely no control over } \\
\text { what I could do with the screen.*^}\end{array}$ & 77/0.75/0.82 & $\begin{array}{l}\text { Liu and } \\
\text { Shrum (2002) }\end{array}$ \\
\hline $\begin{array}{l}\text { Two-way } \\
\text { communication }\end{array}$ & $\begin{array}{l}\text { It is impossible to share my opinion via the screen*^; The } \\
\text { screen makes me feel it wants to listen to its visitors; The } \\
\text { screen gives visitors the opportunity to talk back }\end{array}$ & $0.52 / 0.81 / 0.70$ & $\begin{array}{l}\text { Liu and } \\
\text { Shrum (2002) }\end{array}$ \\
\hline Synchronicity & $\begin{array}{l}\text { When I clicked on the screen, I felt I was getting an } \\
\text { instantaneous response; The screen was very slow in } \\
\text { responding to my requests.*^ }\end{array}$ & $0.37 / 0.75 / 0.83$ & $\begin{array}{l}\text { Liu and } \\
\text { Shrum (2002) }\end{array}$ \\
\hline $\begin{array}{l}\text { Overall perceived } \\
\text { interactivity }\end{array}$ & $\begin{array}{l}\text { On a scale from } 1 \text { (not at all) to } 7 \text { (very), how interactive did } \\
\text { you find the screen? }\end{array}$ & - & - \\
\hline
\end{tabular}

Note(s): * Item was recoded in the analysis, ^ Item was deleted in at least one of the studies to increase the Cronbach's alpha

\begin{tabular}{|c|c|c|c|c|c|}
\hline Construct & Items & $\begin{array}{l}\text { Explained } \\
\text { variance } 1 / 2 \mathrm{a} / \\
2 \mathrm{~b}\end{array}$ & $\begin{array}{l}\text { Cronbach's } \\
\text { alpha } 1 / 2 \mathrm{a} / 2 \mathrm{~b}\end{array}$ & $\begin{array}{l}\text { Based on } \\
\text { scales used } \\
\text { by }\end{array}$ & \\
\hline $\begin{array}{l}\text { Impulse- } \\
\text { buying urge }\end{array}$ & $\begin{array}{l}\text { I feel a strong urge to buy (one of the) } \\
\text { products that the screen displayed; } \\
\text { I want (one of the) products that the } \\
\text { screen displayed; I did not intend to buy } \\
\text { (one of the) displayed products, but now } \\
\text { I do feel the desire to do so }\end{array}$ & $\begin{array}{l}76.26 \% / \\
70.23 \% / \\
74.01 \%\end{array}$ & 0.84/0.79/0.82 & $\begin{array}{l}\text { Sultan et al. } \\
(2012)\end{array}$ & \\
\hline $\begin{array}{l}\text { Impulse-visit } \\
\text { urge }\end{array}$ & $\begin{array}{l}\text { I feel a strong urge to enter this store; } \\
\text { I want to visit this store; I did not intent } \\
\text { to visit this store, but now I feel the } \\
\text { desire to do so }\end{array}$ & $\begin{array}{l}80.24 \% / \\
73.40 \% / \\
73.62 \%\end{array}$ & 88/0.82/0.82 & $\begin{array}{l}\text { Sultan et al. } \\
(2012)\end{array}$ & \\
\hline $\begin{array}{l}\text { Feelings of } \\
\text { self-agency }\end{array}$ & $\begin{array}{l}\text { It felt like I was responsible for what } \\
\text { happened on the screen; It felt like I was } \\
\text { the one influencing what happened on } \\
\text { the screen }\end{array}$ & $\begin{array}{l}90.01 \% / \\
95.32 \% / \\
87.79 \%\end{array}$ & 0.96/0.91/0.86 & $\begin{array}{l}\text { Ruth et al. } \\
\text { (2002) }\end{array}$ & $\begin{array}{r}\text { Table A2. } \\
\text { Measurements key- } \\
\text { constructs experiments } \\
1,2 \mathrm{a} \text { and } 2 \mathrm{~b}\end{array}$ \\
\hline
\end{tabular}

\begin{tabular}{|c|c|c|c|}
\hline Condition & SA & IVU & $\mathrm{IBU}$ \\
\hline \multirow[t]{3}{*}{ Low interactivity } & Exp. 1: $1.88(1.24)^{*}$ & Exp. 1: 3.05 (1.58) & Exp. 1: 2.60 (1.48) \\
\hline & Exp. 2a: 1.75 (1.15)* & Exp. 2a: 2.89 (1.56) & Exp. 2a: 2.51 (1.37) \\
\hline & Exp. 2b: 2.06 (1.40)* & Exp. 2b: 2.94 (1.64) & Exp. 2b: 2.50 (1.35) \\
\hline \multirow[t]{3}{*}{ High interactivity } & Exp. 1: $3.02(1.53)^{*}$ & Exp. 1: 3.15 (1.49) & Exp. 1: 2.28 (1.27) \\
\hline & Exp. 2a: $3.54(1.82)^{*}$ & Exp. 2a: 2.67 (1.35) & Exp. 2a: 2.34 (1.17) \\
\hline & Exp. 2b: 3.44 (1.84)* & Exp. 2b: 3.18 (1.44) & Exp. 2b: 2.88 (1.56) \\
\hline
\end{tabular}

Table A3.

Means and standard deviations of selfagency, impulse-visit urges and impulsebuying urges in low interactivity and high interactivity conditions

Note(s): * Significant difference between low and high interactivity within the same Experiment per experiment 
About the authors

Anne Moes is $\mathrm{Ph}$. D. Candidate at the University of Groningen and serves as a lecturer at the Amsterdam University of Applied Sciences. Her research focuses on impulsive consumer behavior, consumer empowerment and persuasion. She publishes in both scientific journals and trade journals for marketing professionals. Anne Moes is the corresponding author and can be contacted at: a.moes@hva.nl

Marieke Fransen is an Associate Professor at the Amsterdam School of Communication Research (ASCoR), University of Amsterdam. Her research focuses on automatic consumer behavior, consumer resistance and consumer empowerment. She studies these topics from different perspectives and publishes in communication, marketing and consumer-related journals.

Bob Fennis is a Professor of Consumer Behavior at the University of Groningen, the Netherlands. He has published extensively on the psychology of persuasion and social influence, and the role of consumer self-regulation in these processes.

Tibert Verhagen is an Associate professor at the Centre for Market Insights of the Amsterdam University of Applied Sciences. His research interests include emerging digital technology, information systems and store innovation. His research has been published in journals such as Information and Management, European Journal of Information Systems, Journal of the Association for Information Systems, Computers in Human Behavior, Electronic Commerce Research, New Media and Society, and Journal of Retailing and Consumer Services.

Harry van Vliet is a professor at the Amsterdam University of Applied Sciences. As a trained psychologist he holds a $\mathrm{PhD}$ in the humanities from the Utrecht University. He publishes regularly on topics such as consumer experience, media strategy, cross-media, cultural heritage and business model theory. His most recent book publications include: The Fashion Retailscape: innovations in shopping (2015), Media Strategy Game workbook (2016) and The Measurement of Atmospherics (2018).

For instructions on how to order reprints of this article, please visit our website: www.emeraldgrouppublishing.com/licensing/reprints.htm Or contact us for further details: permissions@emeraldinsight.com 